\title{
MRI Evaluation of Tuberculosis of Spine
}

\author{
Rashmi U. Turamari ${ }^{1}$, Pradeep Kumar Chandandur Nagarajaiah ${ }^{2}$, Chakenalli Puttaraju Nanjaraj ${ }^{3}$, N.L. Rajendra \\ Kumar $^{4}$, Sowmya Jagadish ${ }^{5}$, Pradeep Hagalahalli Nagarajegowda ${ }^{6}$, Ashwin Raghavendra ${ }^{7}$ \\ ${ }^{1}$ Resident, ${ }^{2}$ Assistant Professor, ${ }^{3}$ Professor, ${ }^{4}$ Professor and HOD, ${ }^{5}$ Resident, ${ }^{6}$ Associate Professor, ${ }^{7}$ Resident, Department of \\ Radiodiagnosis, Mysore Medical College and Research Institute, Mysuru, India
}

Corresponding author: Pradeep Kumar Chandandur Nagarajaiah, \#32, Chandrodaya, Behind Veerabadreshwara Flour Mill, Bogadi $2^{\text {nd }}$ Stage, Mysuru, Karnataka, India-570009

DOI: 10.21276/ijcmsr.2018.3.3.10

How to cite this article: Rashmi U. Turamari, Pradeep Kumar Chandandur Nagarajaiah, Chakenalli Puttaraju Nanjaraj, N.L. Rajendra Kumar, Sowmya Jagadish, Pradeep Hagalahalli Nagarajegowda, Ashwin Raghavendra. MRI Evaluation of Tuberculosis of Spine. International Journal of Contemporary Medicine Surgery and Radiology. 2018;3(3):C44-C47.

\section{A B S T R A C T}

Introduction: Tuberculosis of spine accounts for $50 \%$ of all musculoskeletal tuberculosis. Magnetic resonance imaging is an excellent imaging modality for the diagnosis of tuberculosis of the spine and can diagnose tuberculosis of the spine four to six months earlier than conventional methods offering the benefits of early detection and treatment. The aim of this study was to evaluate various MR imaging features along with demographic distribution and clinical presentation of spinal tuberculosis.

Material and methods: A descriptive study was carried out on 30 patients who presented with strong clinical suspicion of spinal tuberculosis over a period of 23 months. All subjects underwent plain and contrast-enhanced magnetic resonance imaging. The positive cases of spinal tuberculosis were evaluated on the basis of the signal intensities and morphological abnormalities seen on magnetic resonance imaging.

Result: In this study, male preponderance was noted with a backache being the most common symptom. Seventy percent (21) of cases had epidural involvement, 33.3\% (10) of the patients had endplate irregularity, $26.6 \%$ (8) of patients had a collapse of the vertebral bodies and $10 \%$ (3) of patients had complete destruction of vertebral bodies. Ninety percent (27) patients had intervertebral disc involvement. Pre and paravertebral involvement were noted in $83.3 \%$ (25) of cases and $40 \%$ (12) of cases had psoas abscess.

Conclusion: MRI is a non-invasive investigation of choice in the diagnosis spinal tuberculosis and hence appropriate treatment can be started early

Key words: TB Spine, Epidural Abscess, Intradural Abscess, Gibbus, Vertebral Body Collapse, PSOAS Abscess, Paravertebral Abscess, Endplate Irregularity

\section{INTRODUCTION}

Approximately $10 \%$ of patients with extrapulmonary tuberculosis have skeletal involvement. The spine is the most common skeletal site affected, followed by the hip and knee. ${ }^{1}$ Spinal involvement is usually a result of the hematogenous spread of Mycobacterium tuberculosis into the cancellous bone of the vertebral bodies. The primary infection is either a pulmonary lesion or the lymph node of the mediastinum, mesentery, cervical region, genitourinary system or other viscera. It can result in a collapse of vertebrae and fracture of bones leading to neurological damage. In advanced untreated cases, this can lead to compression of the spinal cord and complete paralysis.

Magnetic resonance imaging is an excellent imaging modality for the diagnosis of tuberculosis of the spine. It is more sensitive and specific because of multiplanar imaging which reveals better diagnostic details. The aim of this study was to evaluate role of Magnetic resonance imaging in diagnosis of spinal tuberculosis, various MR imaging features that help in differentiating between the various stages of disease progression along with demographic distribution and clinical presentation of spinal tuberculosis. Contrast enhancement is best seen on T1-weighted fat saturation sequences, where there is enhancement of only those tissues that takes up the Gadolinium. Contrast enhancement is helpful to define para spinal and epidural disease ${ }^{2}$ and is useful to assess the extent of soft tissue mass. ${ }^{3}$

\section{MATERIAL AND METHODS}

A descriptive study was carried out on 30 patients over a period of 23 months from November 2015 to September 2017 in Department of Radiodiagnosis, Mysore Medical College and Research Institute, Mysuru. Institute Ethics Committee Clearance was obtained before the start of the study.

\section{Patient selection criteria}

The study included patients from 2 to 80 years of age including both men and women with or without neurological 
deficit at spinal level with strong clinical suspicion of spinal tuberculosis.

Patients with a history of trauma were not a part of this study. Also, patients with a history of claustrophobia, the history of metallic implants, cardiac pacemakers and cochlear implant in-situ were excluded from this study.

\section{Method}

The MRI examination of the spine was performed using standard surface coils and body coils, of GE Optima MR360, 1.5 Tesla. Detailed clinical history, physical and systemic examination findings were noted in addition to the laboratory investigations. Patients fulfilling the inclusion and exclusion criteria underwent plain and contrast-enhanced Magnetic resonance imaging.

\section{Scanning technique}

MRI examination of the spine was performed in the sagittal, coronal and axial planes. T1, T2, STIR and post contrast $\mathrm{T} 1$ sequences were obtained. A slice thickness of $4 \mathrm{~mm}$ was used for both sagittal and axial images. A field of view of 350 $\mathrm{mm}$ and $200 \mathrm{~mm}$ was used for the sagittal and axial images, respectively. Omniscan (Gadodiamide) was intravenously injected in all cases of suspected tuberculosis.

\section{STATISTICAL ANALYSIS}

Descriptive statistics were presented using percentages and frequencies for nominal data while meaning, standard deviation, median, minimum and maximum for continuous/ discrete variables. The results were presented in figures, tables, frequency graphs and pie charts.

\section{RESULTS}

Out of the 30 patients, the majority of patients belonged to the third and fourth decades, the percentage is 30\% and the majority were male patients (57\%). Backache was the main mode of presentation followed by combined symptoms including backache, weight loss, and fever. Neurological complaints were present in $8 \%$ (4) of cases, $16 \%$ (5) of cases had past history of tuberculosis, $13.3 \%$ (4) cases had concurrent pulmonary tuberculosis and 6.6\% (2) patients had the retroviral infection.

The most common presentation was two vertebral involvements, seen in 20 patients (66.6\%). Lumbar region is the most common region of involvement with $70 \%$ (21) cases having epidural involvement. Intradural and intramedullary involvements seen in only 6.6\% (2) cases each (Table I).

All the patients had altered signal changes in the involved vertebra, 33.3\% (10) of the patients had endplate irregularity,

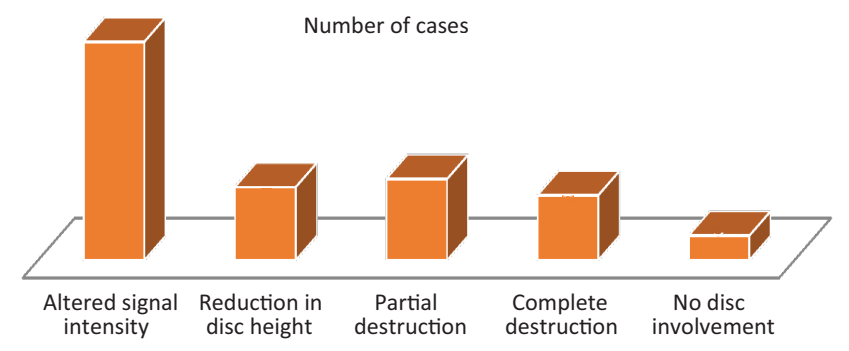

Chart-I: Chart showing the MR imaging features of intervertebral disc involvement
$26.6 \%$ (8) of patients had the collapse of the vertebral bodies and $10 \%$ (3) of patients had complete destruction of vertebral bodies. About 6.6\% (2) of patients had already developed kyphotic deformities at the time of examination (Table II).


Case-1: Clinical history: History of back ache (Sagittal T2WI image shows altered signal intensities involving L4-L5 disco vertebral unit, with complete collapse of L4L5 disc, with pre and para-vertebral collection indenting on the thecal sac posteriorly.) Case-2: Clinical history: History of back ache (Sagittal T2 image showing multiple level involvements. Altered signal intensity noted in D4, D5 andD6 vertebrae with partial destruction of D5-D6 disc with partial collapse of D5 vertebra. Peripherally enhancing pre-vertebral and epidural abscess with adjacent cord edema is also noted. Altered signal intensity and anterior wedge collapse of D12 vertebra is noted.)

\begin{tabular}{|l|c|c|}
\hline & No. of cases & Percentage \\
\hline Epidural abscess & 21 & $70 \%$ \\
\hline Intradural involvement & 2 & $6.6 \%$ \\
\hline Intramedullary involvement & 2 & $6.6 \%$ \\
\hline
\end{tabular}

Table-1: Table showing the dural, extradural and intramedullary involvement of spinal tuberculosis.

\begin{tabular}{|l|c|c|}
\hline Imaging features & $\begin{array}{c}\text { Number } \\
\text { of cases }\end{array}$ & Percentage \\
\hline Altered signal changes only & 30 & $100 \%$ \\
\hline End plate irregularity & 10 & $33.3 \%$ \\
\hline $\begin{array}{l}\text { Vertebral body collapse/Compres- } \\
\text { sion fracture }\end{array}$ & 8 & $26.6 \%$ \\
\hline $\begin{array}{l}\text { Complete destruction of the verte- } \\
\text { bral body }\end{array}$ & 3 & $10 \%$ \\
\hline $\begin{array}{l}\text { Spinal deformity } \\
\text { (kyphosis) }\end{array}$ & 2 & $6.6 \%$ \\
\hline $\begin{array}{l}\text { Table-2: Table showing the severity of vertebral body involve- } \\
\text { ment }\end{array}$ \\
\hline
\end{tabular}

\begin{tabular}{|l|c|c|}
\hline MRI features & $\begin{array}{c}\text { No. of } \\
\text { cases }\end{array}$ & Percentage \\
\hline Prevertebral abscess & 25 & $83.3 \%$ \\
\hline Paravertebral abscess & 25 & $83.3 \%$ \\
\hline Psoas abscess & 12 & $40 \%$ \\
\hline No pre and paravertebral abscess & 5 & $16.6 \%$ \\
\hline \multicolumn{2}{|c|}{ Table-3: Table showing pre and paravertebral soft tissue } \\
involvement \\
\hline
\end{tabular}



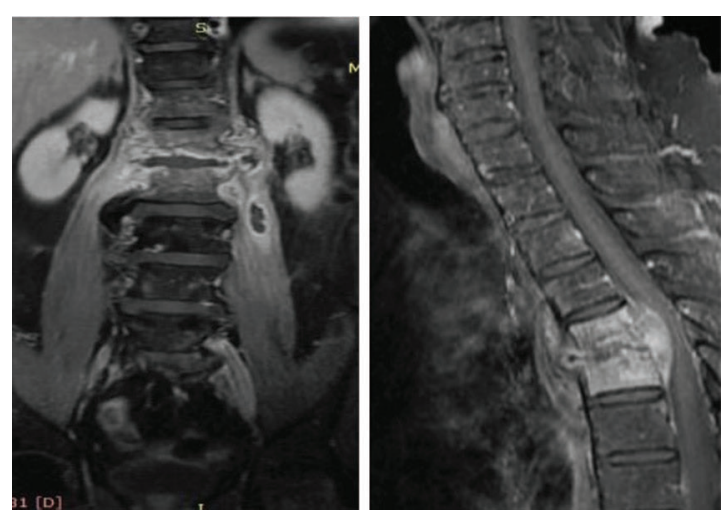

Case-3: Clinical history: History of back ache (Coronal $\mathrm{T} 1+\mathrm{C}$ showing bilateral psoas muscle abscesses with enhancement of L1 and L2 vertebrae and partial collapse of L1-L2 disc.) Case-4: Clinical history: History of back ache (Sagittal T1+C image showing complete destruction of D5D6 intervertebral disc. Heterogeneous enhancement and partial collapse of D5 vertebra, pre-vertebral and epidural abscess and dorsal cord compression can also be noted.)

Ninety percent (27) patients had intervertebral disc involvement and all the patients showed altered signal intensities. Reduced intervertebral disc space was observed in 30\% (9) patients, 33.3\% (10) patients had partial destruction and $26.6 \%$ (8) patients had complete destruction of the intervertebral disc and 3 patients did not show disc involvement (Chart I).

In this study, 83.3\% (25) of cases had pre and paravertebral involvement and 40\% (12) cases had frank psoas abscess. In $16.6 \%$ (5) of cases pre and paravertebral involvement was not seen (Table III). In this study, $83.33 \%$ patients had thecal compression. Cord edema noted as the increasedT2 signal is seen in 20\% (6) cases and cord compression is seen in 36.6\% (11) of cases (case photographs 1-4).

\section{DISCUSSION}

Tuberculosis is the most common infection worldwide and it can affect almost any part of the human body, most commonly the lungs. The spine is affected in $50 \%$ of the cases of skeletal tuberculosis. Tuberculous infection of the spine causes bony destruction and collapse of the vertebrae, with a gibbus or kyphotic deformity, skip lesions, intervertebral disc involvement, epidural abscess, paravertebral abscess, psoas abscess ${ }^{4}$ and edema in the soft tissue planes. Magnetic Resonance Imaging is the most valuable investigation in the patients with spinal tuberculosis, as it can clearly demonstrate all of the above findings.

In this study, $60 \%$ of patients were having lumbar spinal involvement and the next common was $23.3 \%$ involving thoracic vertebral bones, $10 \%$ patients had involvement of thoracolumbar and only $3.33 \%$ patients had multiple level involvement of the spine. Total of 72 vertebrae was affected in 30 patients. An average number of vertebrae affected per patient was 2.26 .

In this study, the maximum number of patients belonged to the age group 30-40 years and next common age group was between 20-30 years, which was similar to study done by Ferrer MF et al. ${ }^{5}$ Back pain was the presenting symptom in $70 \%$ of the cases and other common complaints were neurological symptoms, fever, and weight loss. Past history of tuberculosis was present in $16.6 \%$ of the patients and $13.3 \%$ of patients had active pulmonary tuberculosis. In the present study, $6.6 \%$ of the patients were HIV affected patients.

Every patient had altered signal changes in the involved vertebral bodies. Endplate irregularity was noted in 33.3\% of the patients, $13.3 \%$ of patients had the collapse of the vertebral bodies, and $26.6 \%$ of patients had vertebral body collapse and compression fracture and $10 \%$ of patients had complete destruction of vertebral bodies. About $6.6 \%$ of patients had already developed spinal deformities at the time of examination. Similar studies done by Sajid Ansari et al. shows that $26.7 \%$ of patients had spinal deformity and $6 \%$ of patients had complete destruction of vertebral bodies. ${ }^{6}$

Ninety percent (27) of patients had intervertebral disc involvement and all the patients showed altered signal intensities, 30\% (9) patients had reduced intervertebral disc height, 33.3\% (10) patients had partial destruction and 26.6\% (8) patients had complete destruction of the intervertebral discs, 3 (10\%) patients had no disc involvement.

A study conducted by Sinan et al. ${ }^{7}$ shows involvement of intervertebral discs in $72 \%$ of cases and a study by Ledermann et al $(2003)^{8}$ showed decreased height of intervertebral disc space in $50 \%$ of cases.

Due to lack of proteolytic enzymes subligamentous spread along the anterior and posterior ligaments is common in spinal tuberculosis. Posteriorly it can involve extradural or intradural region or may involve spinal cord. The lesion is called granulation tissue when it showed hypo to intermediate signal intensity on T1W images, hyperintensity on T2W images and homogenous enhancement on post gadolinium images. ${ }^{9}$

Formation of cold abscess and involvement of pre and paravertebral soft tissue favors the diagnosis of spinal tuberculosis. If the infection is not controlled by early intervention, adjacent muscle involvement occurs resulting in psoas abscess. Calcification or bone fragments within the pre /paravertebral soft tissue are called 'rice bodies', specific for a tubercular abscess. They are identified as small areas of signal void on T2W images. Presence of 'rice bodies' within the pre and the paraspinal abscess was reported in the literature by Huang et al. ${ }^{10}$

In all the cases of this study contrast enhancement examination was done using Gadolinium (Omniscan) and T1 sagittal and axial images were taken. Two types of contrast enhancement were observed in the present study.

Heterogenous enhancement of involved vertebral bodies and intervertebral discs.

Ring like peripheral enhancement of involved vertebral bodies and intervertebral discs.

Epidural and pre and paravertebral collections show rim enhancement with central hypointense areas of necrosis. It has been reported that thick rim enhancement in these abscesses is strongly suggestive of tuberculous infection and is not seen in non-granulomatous spondylitis. ${ }^{11}$

Spinal cord involvement was very clearly seen on sagittal and axial MR images. 83.33\% (25/30) patients had thecal compression. Out of which $36.67 \%$ (11/30) had actual cord 
compression. Cord edema is seen as increased T2 signal intensity and was present in $20 \%(6 / 30)$ patients. Thus in decreasing order of frequency, the progression of compression was thecal compression, cord compression, and cord edema. The high signal on T2 W images within the cord could represent either cord edema or myelomalacia. It is important to differentiate these two entities because edema is reversible whereas myelomalacia is not. Unfortunately, based on imaging appearance alone it was not possible to differentiate between cord edema and myelomalacia and clinical history and duration of disease have to be taken into account. ${ }^{12,13}$ Sharif et $\mathrm{a}^{14}$ have reported a higher incidence of arachnoiditis in their study (33\%). Sharma et $\mathrm{al}^{15}$, however, reported that only $9 \%$ of tubercular spinal arachnoiditis in their study, which was caused by spinal tuberculosis. Dorsal region was the commonest site of involvement in both these studies. On T1W images arachnoiditis is seen as shaggy cord-CSF interface. On post- gadolinium images there was a meningeal enhancement. However, arachnoiditis, as a complication of spinal tuberculosis was not seen in any of the patients in this study.

Our study showed that MRI is an accurate modality in diagnosing and evaluating spinal tuberculosis in early stages and serial MRI scans can also be used to assess the disease response to treatment which is comparable to many studies. Limitation of our study was follow up of a few patients could not be done.

\section{CONCLUSION}

MRI imaging findings are helpful in diagnosing as well as evaluating the extent of spinal tuberculosis. MRI should be considered as the first line imaging modality for patients with suspected spinal tuberculosis, as it provides necessary information to the surgeon for proper management by providing accurate vertebral involvement, intra-osseous abscess, vertebral disc involvement, skip lesions, early soft tissue involvement, spinal cord affection, dural and intradural involvement.

MRI is an accurate modality in diagnosing and evaluating spinal tuberculosis in early stages and serial MRI scans can also be used to assess the disease response to treatment.

\section{REFERENCES}

1. Bajwa GR. Evaluation of the role of MRI in spinal Tuberculosis: A study of 60 cases. Pak J Med Sci. 2009; 25(6):944-7.

2. Khalequzzaman SI, Hoque HW. Tuberculosis of Spine Magnetic Resonance Imaging (MRI) Evaluation of 42 Cases. Medicine Today. 2013; 24(2):59-62.

3. Ansari S, Rauniyar RK, Dhungel K, Sah PL, Chaudhary $\mathrm{P}$, Ahmad $\mathrm{K}$ et al. MR evaluation of spinal tuberculosis. Al Ameen J Med Sci. 2013; 6(3):219-25.

4. Shanley DJ. Tuberculosis of the spine: imaging features. AJR. Am J Roentgenol. 1995;164:659-64.

5. Ferrer MF, Torres LG, Ramírez OA, Zarzuelo MR, del Prado González N. Tuberculosis of the spine. A systematic review of case series. Int Orthop. 2012;36(2):221-31.

6. Ansari S, Rauniyar RK, Dhungel K, Sah PL, Chaudhary $\mathrm{P}$, Ahmad K et al. MR evaluation of spinal tuberculosis.
Al Ameen J Med Sci. 2013;6(3):219-25.

7. Sinan T, Al-Khawari H, Ismail M, Ben-Nakhi A, Sheikh M. Spinal tuberculosis: CT and MRI feature. Ann Saudi Med. 2004;24(6):437-41.

8. Bhojraj S, Nene A. Lumbar and lumbosacral tuberculousspondylodiscitis in adults. J Bone Joint Surg 2002;84(4):530-4.

9. Kim NH, Lee HM, Suh JS. Magnetic resonance imaging for the diagnosis of tuberculous spondylitis. Spine. 1994;19(21):2451-5.

10. Huang YC, Shih TT, Huang KM, Su CT. Infectious spondylitis: MRI characteristics. J Formos Med Assoc 1996; 95(6):458-63.

11. Prakash ML, Sarwagi R, Srilatha K. Spinal intramedullary tuberculoma: typical, atypical presentation on magnetic resonance imaging. Journal of Case Reports. 2013; 3(2):404-9.

12. Cotten A, Flipo RM, Drouot MH, Maury F, Chastanet P, Duquesnoy B et al Spinal tuberculosis. Study of clinical and radiological aspects from a series of 82 cases.Journal de radiologie. 1996;77(6):419-26.

13. Le Page L, Feydy A, Rillardon L, Dufour V, Le Hénanff A, Tubach $\mathrm{F}$ et al. Spinal tuberculosis: a longitudinal study with clinical, laboratory, and imaging outcomes. Semin Arthritis Rheum 2006; 36:124-9

14. Sharif HS, Aideyan OA, Clark DC, Madkour MM, Aabed MY,Mattsson TA et al. Brucellar and tuberculous spondylitis: comparative imaging features. Radiology. 1989;171(2):419-25.

15. Sharma S, Gupta SK, Varshney A, Sharma A, Bansal A, Choudhary A. A Study of Osteoarticular Tuberculosis in a Tertiary Care Hospital of Bhopal, Madhya Pradesh. Natl J Community Med 2013; 4(1): 117-20.

Source of Support: Nil; Conflict of Interest: None

Submitted: 06-06-2018; Accepted: 08-07-2018; Published online: 13-08-2018 